\title{
RAFT Polymerization of $N$-Vinyl Pyrrolidone Using Prop-2-ynyl Morpholine-4-carbodithioate as a New Chain Transfer Agent
}

\author{
Vivek Mishra, Rajesh Kumar \\ Organic Polymer Laboratory, Department of Chemistry, Centre of Advanced Studies in Chemistry, \\ Banaras Hindu University, Varanasi-221005, UP, India
}

Received 29 April 2011; accepted 9 August 2011

DOI 10.1002/app.35480

Published online 2 December 2011 in Wiley Online Library (wileyonlinelibrary.com).

\begin{abstract}
RAFT polymerization of $N$-vinyl pyrrolidone (NVP) has been investigated in the presence of chain transfer agent (CTA), i.e., prop-2-ynyl morpholine-4-carbodithioate (PMDC). The influence of reaction parameters such as monomer concentration [NVP], molar ratio of [CTA]/[AIBN, i.e., 2,2'-azobis (2-methylpropionitrile)] and $[\mathrm{NVP}] /[\mathrm{CTA}]$, and temperature have been studied with regard to time and conversion limit. This study evidences the parameters leading to an excellent control of molecular weight and molar mass dispersity. NVP has been polymerized by maintaining molar ratio [NVP]: [PMDC]: $[\mathrm{AIBN}]=100: 1: 0.2$. Kinetics of the reaction was
\end{abstract}

strongly influenced by both temperature and [CTA]/ [AIBN] ratio and to a lesser extent by monomer concentration. The activation energy $\left(E_{a}=31.02 \mathrm{~kJ} \mathrm{~mol}^{-1}\right)$ and enthalpy of activation $\left(\Delta H^{\ddagger}=28.29 \mathrm{~kJ} \mathrm{~mol}^{-1}\right)$ was in a good agreement to each other. The negative entropy of activation $\left(\Delta S^{\ddagger}=-210.16 \mathrm{~J} \mathrm{~mol}^{-1} \mathrm{~K}^{-1}\right)$ shows that the movement of reactants are highly restricted at transition state during polymerization. (c) 2011 Wiley Periodicals, Inc. J Appl Polym Sci 124: 4475-4485, 2012

Key words: living polymerization; dithiocarbamate; $\mathrm{N}$-vinyl pyrrolidone; activation energy

\section{INTRODUCTION}

The thiocarbonylthio moieties have been found effective in controlling the polymerization by reversible addition-fragmentation chain transfer $(\mathrm{RAFT})^{1,2}$ process. There have been a number of publications ever since, clearly indicating the versatility of the RAFT systems using various monomers in both homogeneous and heterogeneous environments. A book by Chiefari and Rizzardo on radical polymerization comprises a chapter, which deals with the work done in the RAFT area. ${ }^{3}$ RAFT agents (also called chain-transfer agents) must be thiocarbonylthio compounds where the $\mathrm{Z}$ and $\mathrm{R}$ groups perform different functions. The $Z$ group primarily controls the ease with which radical species add to the $C=S$ bond. The $\mathrm{R}$ group plays an important role-it must be a good homolytic leaving group which is able to initiate new polymer chains. There are four classes of thiocarbonylthio RAFT agents, depending on the nature of the activating $(\mathrm{Z})$ group: (i) dithioesters $(\mathrm{Z}=$ aryl or alkyl), (ii) trithiocarbonates ( $Z=$ substituted sulfur),

\footnotetext{
Correspondence to: R. Kumar (rkr_bhu@yahoo.com).

Contract grant sponsor: DST, New Delhi; contract grant number: SR/FTP/CS-107/2005.
}

Journal of Applied Polymer Science, Vol. 124, 4475-4485 (2012) (C) 2011 Wiley Periodicals, Inc. (iii) dithiocarbonates (xanthates, i.e., $\mathrm{ROC}(=\mathrm{S}) S \mathrm{R}^{\prime}$ ) and (iv) dithiocarbamates ( $\mathrm{Z}=$ substituted nitrogen). The combination that would be the best suited for specific monomers has been also found.

In a RAFT mechanism, initiation occurs via the decomposition of the free radical initiator leading to formation of propagating chains. This is followed by addition of the propagating radical to the RAFT agent. Further, the fragmentation of the intermediate radical occurs, giving rise to a polymeric RAFT agent and new radical. This radical reinitiates the polymerization to form new propagating radicals. The RAFT process relies on this rapid central addition fragmentation equilibrium between propagating and intermediate radicals, and chain activity and dormancy as shown in Scheme 1. ${ }^{4}$

Before the invention of controlled radical polymerization, the vinyl monomers were polymerized through conventional (redox) free radical polymerization process to prepare copolymers ${ }^{5,6}$ and homopolymers. Conventional free radical polymerization has some drawbacks such as high molar mass dispersity, formation of side products, and uncontrollability of reaction. Controlled/living radical polymerization methods $s^{7,8,10-20}$ has been explored widely for the controlled synthesis of homopolymers and block copolymers. Rizzardo et al. ${ }^{7}$ reported first in a patent about reversible addition-fragmentation chain transfer (RAFT) polymerization of NVP. Later, 


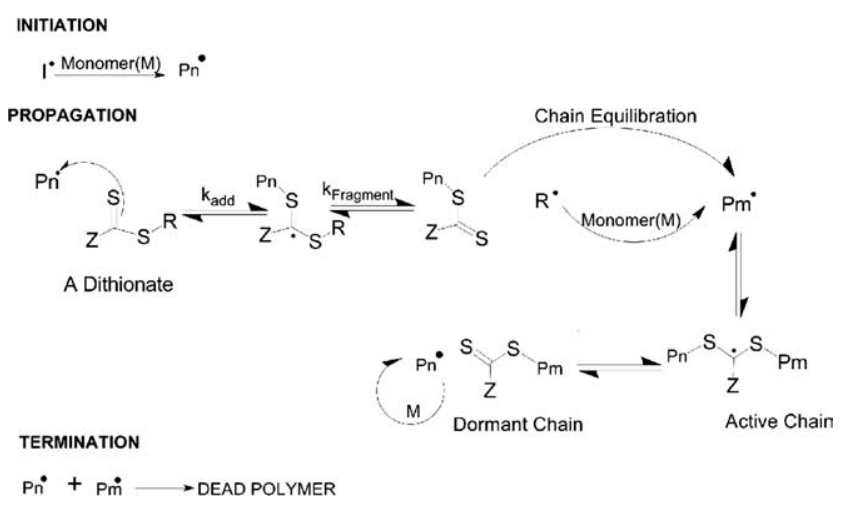

Scheme 1 RAFT equilibrium during polymerization process.

Matyzaszewski et al. ${ }^{8}$ reported the synthesis of low molecular weight and low molar mass dispersity $\left(M_{n}=2000,{\bigoplus m^{9}}^{2}=1.15\right)$ poly(NVP) using coppercatalyzed atom transfer radical polymerization (ATRP). In both reports, details have not been disclosed. Using xanthate-type RAFT agent, Kamigaito et al. $^{10}$ reported the controlled radical polymerization of NVP as well as the simultaneous control of molecular weight of poly(NVP) by performing polymerization in fluoroalcohols. Gnanou et al. ${ }^{11}$ also reported the controlled radical polymerization of NVP using dithiocarbamate-type RAFT agents. Hadjichristidis et al. ${ }^{12}$ also reported the controlled radical polymerization of NVP using nitroxidemediated and RAFT polymerization methods. However, they did not report so far the detailed study of the RAFT polymerization of NVP.

NVP is neither a skin sensitizer nor a primary irritant. Generally, N-vinyl-2-pyrrlidone imparts desirable properties when as little as $1.20 \%$ is polymerized with another monomer or monomer grafted on the polymeric backbone. Incorporation of high molecular weight poly( $N$-vinyl pyrrolidone) increases the transparency of polyamides and improves dye receptivity of cellulose derivatives. Combination of cellulose and poly( $N$-vinyl pyrrolidone) is also used as hemodialysis membranes. ${ }^{21,22}$ Its suspending ability is a chief reason for its wide use in pill tabelating, capsule granulation and in amitriptyline- 25 tablet formulation on drug dissolution. ${ }^{23}$ Poly( $N$-vinyl pyrrolidone) is used in the preparation of odor masking compound, ${ }^{24}$ thus acting as odor neutralizer in aerosol deodorants to remove unpleasant odors of human and animal hair. NVP is also widely used in cosmetics, $^{25}$ textiles, ${ }^{26}$ and pharmaceuticals. ${ }^{27}$

Present investigation was undertaken to study in detail the living and controlled polymerization of $N$-vinyl pyrrolidone with narrow molar mass dispersity, which can have better applications than the polymer formed by uncontrolled polymerization process. This prompted us to carry out the synthesis of new RAFT agent and their application in controlled radical polymerization of $N$-vinyl pyrrolidone by RAFT process. In the present work, synthesis of new chain transfer agent, i.e., prop-2-ynyl morpholine-4-carbodithioate, characterization and optimization of reaction conditions of polymerization process to get narrow molar mass dispersity of poly ( $N$-vinyl pyrrolidone) which could have better application than the polymer formed by uncontrolled polymerization process and kinetics of controlled process in detail is being reported.

\section{EXPERIMENTAL}

\section{Materials}

Morpholine (99\%, Merck) has been stored over metallic sodium under $\mathrm{N}_{2}$ atmosphere for $24 \mathrm{~h}$ and finally distilled under reduced pressure. 2, 2'-Azobis (2-methylpropionitrile) (AIBN) (Fluka, 98\%) has been purified by recrystallization from ethanol. Tetrahydrofuran (THF; 99.8\%, Merck) has been dried and distilled over benzophenone and sodium. Propargyl bromide ( $80 \mathrm{wt} \%$ in toluene, Aldrich), dry dimethyl formamide (DMF; 99.8\%, Merck), N-vinyl pyrrolidone (NVP; 99\%, Aldrich), carbon disulfide $\left(\mathrm{CS}_{2}\right)$, sodium hydroxide $(\mathrm{NaOH})$ have been used as received. Other solvents have been purified by conventional procedures.

All the reaction parameters have been calculated by following formulae:

$$
\text { Conversion }_{\mathrm{NMR}}=\frac{A_{\text {Polymer }}}{A_{\text {Polymer }}+A_{\text {Monomer }}}
$$

All the monomer conversion for the kinetic study have been estimated by ${ }^{1} \mathrm{H}$ NMR with the samples directly withdrawn at time intervals, the monomer conversion being estimated by comparing the peak areas of the monomer and homopolymer. The exact monomer conversion and $M_{n}$ NMR of polymers can be calculated using eqs. 1 and 2 .

$$
\begin{aligned}
M_{n(\mathrm{NMR})}=M_{\mathrm{PMDC}}+M_{\mathrm{NVP}} \times \frac{[\mathrm{NVP}]_{0}}{[\mathrm{PMDC}]_{0}} \\
\times \text { Conversion }_{\mathrm{NVP}}
\end{aligned}
$$

The theoretical number-average molecular weight on conversion is defined as follows:

$$
\begin{array}{r}
M_{n(\mathrm{THEO})}=\frac{[\mathrm{NVP}]_{0}}{[\mathrm{PMDC}]_{0}+2 f[\mathrm{I}]_{0}\left(1-e^{-k_{d} t}\right)} \times M_{\mathrm{NVP}} \\
\times \text { Conversion }_{(\mathrm{NVP})}+M_{\mathrm{PMDC}}
\end{array}
$$

in which $M_{\mathrm{PMDC}}$ and $M_{\mathrm{NVP}}$ are molecular weights of chain transfer agent and the monomer, whereas 
$[\mathrm{NVP}]_{0}$ and $[\mathrm{PMDC}]_{0}$ are the initial concentrations of the monomer and chain transfer agent, respectively. The right-hand side of the denominator accounts for radicals derived from initiator with an initial concentration $[I]_{0}$ at time $t$ with a decomposition rate, $k_{d}$. The initiator efficiency is represented by $f$. In an ideal RAFT process, polymer directly derived from the initiators is minimal, and thus the second term in the denominator becomes negligible ${ }^{28-30}$ and eq. 3 can be simplified to eq. 4 .

$$
\begin{aligned}
& M_{n(\text { theo })}=\frac{[\mathrm{NVP}]_{0}}{[\mathrm{PMDC}]_{0}} \times M_{\mathrm{NVP}} \\
& \times \text { Conversion }_{(\mathrm{NVP})}+\mathrm{M}_{\mathrm{PMDC}} \\
& M_{n(\mathrm{UV})}=\frac{w}{c_{\mathrm{PMDC}}}
\end{aligned}
$$

where $w$ is the weight of polymer ${ }^{31}$ sample analyzed (in g), $C_{\text {PMDC }}$ is the amount of PMDC residues in the polymer sample (in mol) determined experimentally by application of Beer's law and using the molar extinction coefficient of PMDC. The absorbance of polymer was recorded and the concentration of PMDC was calculated using the molar extinction coefficient of PMDC determined above.

$$
\begin{aligned}
\text { Initiator efficiency }(f) & =M_{n(\mathrm{THEO}) / M_{n(\mathrm{GPC})}} \\
\text { Degree of Polymerization }\left(\mathrm{DP}_{n}\right) & =\frac{[\mathrm{NVP}]_{0}}{[\mathrm{PMDC}]_{0}} \\
& \times \text { Conversion }_{(\mathrm{NVP})}
\end{aligned}
$$

It is a well-known fact that raising the temperature increases the reaction rate, though, quantitatively, activation energy and frequency factor are determined by the Arrhenius eq. 8 :

$$
k=A \cdot e^{-\frac{E_{a}}{R T}}
$$

where $E_{a}=$ activation energy, $R=8.314\left[\mathrm{~J} \mathrm{~mol}^{-1} \mathrm{~K}^{-1}\right.$ ], $T=$ absolute temperature in $\mathrm{K}, A=$ frequency factor, $A=p Z$, where $Z$ is the collision rate and $p$ is a steric factor. $Z$ turns out to be only weakly dependant on temperature. Thus, the frequency factor is a constant, specific for each reaction.

The Eyring equation is calculated from eq. 9:

The linear form of the Eyring equation is

$$
\ln \frac{k}{T}=-\frac{\Delta H^{\ddagger}}{R T}+\ln \frac{k_{B}}{h}+\frac{\Delta S \ddagger}{R}
$$

where $k_{B}=$ Boltzmann's constant $\left[1.381 \times 10^{-23}\right.$ $\left.\mathrm{JK}^{-1}\right], T=$ absolute temperature in $\mathrm{K}, h=$ Plank constant $\left[6.626 \times 10^{-34} \mathrm{~J} \mathrm{~s}\right]$.

A plot of $\ln (k / T)$ versus $1 / T$ produces a straight line then $y=-m x+b$, where $(x=1 / T)$. Activation of enthalpy $\left(\Delta H^{\ddagger}\right)$ can be calculated from the slope $m$ of this line: $\Delta H^{\ddagger}=-m R$.

From the $y$-intercept,

$$
y(x=0)=\ln \frac{k_{B}}{h}+\frac{\Delta S \ddagger}{R}
$$

Activation of entropy $\left(\Delta S^{\ddagger}\right)$ can be determined and thus the calculation of $\Delta G^{\ddagger}$ for the appropriate reaction temperatures according to eq. 11 is allowed.

$$
\Delta G^{\ddagger}=\Delta H^{\ddagger}-T \cdot \Delta S^{\ddagger}
$$

where $R=$ universal gas constant $=8.3145\left[\mathrm{~J} \mathrm{~mol}^{-1}\right.$ $\left.\mathrm{K}^{-1}\right], \Delta G^{\ddagger}=$ free activation enthalpy $\left[\mathrm{kJ} \mathrm{mol}^{-1}\right], \Delta S^{\ddagger}$ $=$ activation entropy $\left[\mathrm{J} \mathrm{mol}^{-1} \mathrm{~K}^{-1}\right], \Delta H^{\ddagger}=$ activation enthalpy $\left[\mathrm{kJ} \mathrm{mol}{ }^{-1}\right]$.

\section{Techniques of characterization}

${ }^{1} \mathrm{H}$ NMR spectra were recorded on a JEOL AL300 NMR spectrometer at $25^{\circ} \mathrm{C}$ in $\mathrm{CDCl}_{3}$ as solvent at $300 \mathrm{MHz}$ and are reported in parts per million (ppm) from internal tetramethylsilane. FTIR spectra of the samples were recorded by making pellets in $\mathrm{KBr}$ and in neat using Varian Excalibur 3100 spectrometer (Palo Alto, CA) in the $400 \mathrm{~cm}^{-1}$ to $4000 \mathrm{~cm}^{-1}$ region with $4 \mathrm{~cm}^{-1}$ resolution and 32 scans. UV-vis spectra were recorded on PerkinElmerLambda $35 \mathrm{UV}$-vis Spectrophotometer at $25^{\circ} \mathrm{C}$. The optical path length of measurement cell was $10 \mathrm{~mm}$. The number average molecular weight $\left(M_{n}\right)$ and molar mass dispersity (Đm) were determined by Younglin ACME 9000 Gel Permeation Chromatography in DMF at $40^{\circ} \mathrm{C}$ with flow rate $1 \mathrm{~mL} / \mathrm{min}$ on two polystyrene gel columns [PL gel $5 \mathrm{~lm} 10 \mathrm{E} 4 \AA$ columns $(300 \times 7.5 \mathrm{~mm})]$ connected in series to Younglin ACME 9000 Gradient Pump and a Younglin ACME 9000 RI detector. The columns were calibrated against poly(methyl methacrylate) (PMMA) standard samples (Polymer Lab, PMMA Calibration Kit, M-M-10).

\section{Synthesis of prop-2-ynyl morpholine-4-carbodithioate: A RAFT agent}

Morpholine (17.40 g, $0.20 \mathrm{~mol})$ and methanol $(20 \mathrm{~mL})$ were added into a 100-mL Erlenmeyer flask and the solution was cooled to $0^{\circ} \mathrm{C}$ in an ice bath (Scheme 2). Carbon disulfide (7.60 g, $0.10 \mathrm{~mol})$ was added dropwise through a pressure equalizing dropping funnel over $30 \mathrm{~min}$ with vigorous stirring, then a solution of $\mathrm{NaOH}(4 \mathrm{~g}, 0.10 \mathrm{~mol})$ in $20 \mathrm{~mL}$ methanol was added and the mixture was stirred at $60^{\circ} \mathrm{C}$ for $1 \mathrm{~h}$ under high purity nitrogen and stirred until the $\mathrm{NaOH}$ was completely dissolved. About threequarters of the methanol were removed using a 

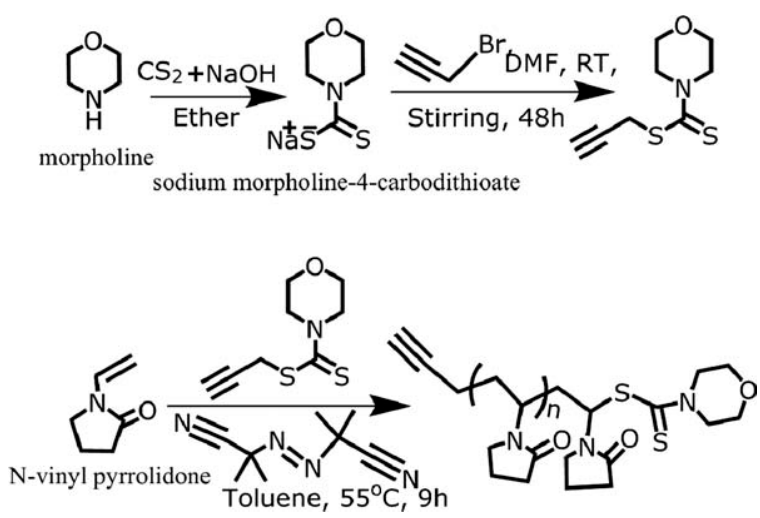

Scheme 2 Experimental conditions for RAFT polymerization process for NVP.

rotavapor. The mixture was chilled and poured into $40 \mathrm{~mL}$ of diethyl ether. The white precipitate (sodium salt of morpholine dithiocarbamic acid $\left(\mathrm{MDC}^{-} \mathrm{Na}^{+}\right)$) was filtered and dried at $40^{\circ} \mathrm{C}$ for $2 \mathrm{~h}$ under vacuum. This precipitate was dissolved into $10 \mathrm{~mL}$ of dry toluene. Propargyl bromide $(11.8 \mathrm{~g} / 15.75 \mathrm{~mL}, 0.1 \mathrm{~mol})$ was added slowly to this reaction mixture of sodium salt of morpholine dithiocarbamic acid. The reaction mixture was degassed by three freeze pump thaw cycles and left in vacuo. The mixture was allowed to stir overnight. The solution was extracted with diethyl ether and then solvent was removed under reduced pressure to get clear yellow liquid (scheme 2). ${ }^{1} \mathrm{H}$ NMR (300 $\left.\mathrm{MHz}, \mathrm{CDCl}_{3}\right): \delta 3.861\left(\mathrm{~s}, 2 \mathrm{H},-\mathrm{CH}^{\mathrm{b}}\right), 3.257-3.384$ $\left(\mathrm{dd}, 8 \mathrm{H},-\mathrm{CH}^{\mathrm{c}, \mathrm{d}}\right), 2.275\left(\mathrm{~s}, 1 \mathrm{H}, \mathrm{CH}^{\mathrm{a}}\right.$ ) (Fig. 1). FT-IR (Neat, $\mathrm{cm}^{-1}$ ): 3294, 3008, 2961, 2633, 2123, 1717, 1619, 1515, 1422, 1291, 1256, 1211, 1148, 1108, 1028, 958, 872, 804 (Fig. 3). UV (in DMSO): 271 and $295 \mathrm{~nm}$ (Fig. 4, curve B).

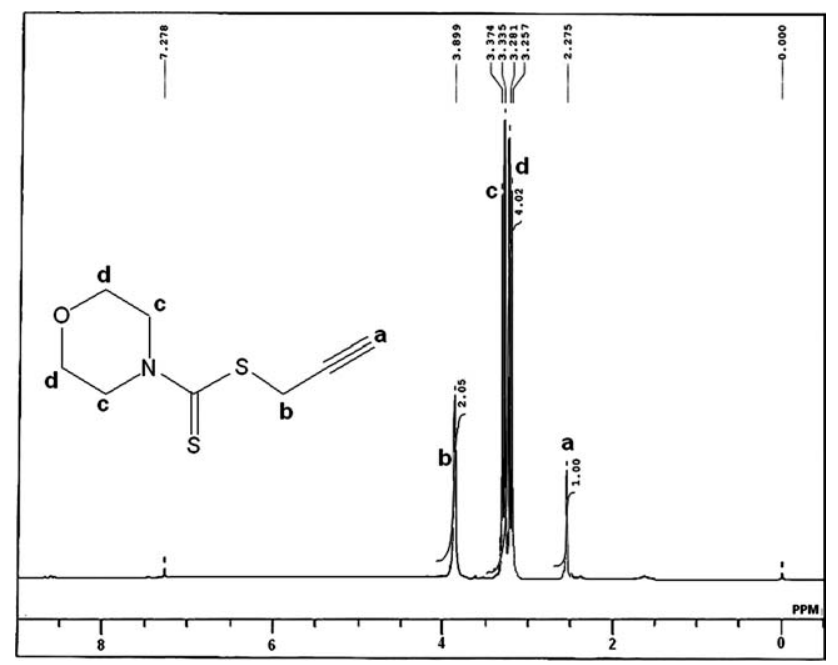

Figure $1{ }^{1} \mathrm{H}$ NMR spectra of prop-2-ynyl morpholine-4carbodithioate (PMDC).
Prop-2-ynyl morpholine-4-carbodithioate mediated RAFT polymerization of NVP and its purification

Eleven milliliters (100 mmol) of distilled $N$-vinyl pyrrolidone (NVP), AIBN initiator $(32.8 \mathrm{mg}, 0.2 \mathrm{mmol}$ ), and chain transfer agent (PMDC; $201 \mathrm{mg}, 1 \mathrm{mmol}$ ) were placed in a dry Schlenk tube equipped with a magnetic stirring bar, and then the solution was degassed by three freeze-evacuate-thaw cycles. The flask was immersed in a preheated oil bath at $55^{\circ} \mathrm{C}$ for desired time. The color of the solution changed from colorless to yellow and to brown. After definite time intervals, a small portion of the reaction mixture was taken out to determine the monomer conversion by ${ }^{1} \mathrm{H}$ NMR. Rapid cooling with liquid nitrogen stopped the reaction. For the determination of the monomer conversion, polymer was precipitated in hexane. For purification of polymer, precipitate was dissolved in minimum amount of DMF and reprecipitated into excess of hexane. The conversion determined by this method was $72 \%$. The resulting polymer was soluble in methanol, $\mathrm{CHCl}_{3}, \mathrm{DMSO}, \mathrm{DMF}$, and basic water. The rest of the polymer mixture was dissolved in THF and precipitated from excess amount of hexane. The precipitated polymer was collected by centrifugation. The separated polymer was dried under vacuum at $50^{\circ} \mathrm{C}$ for $12 \mathrm{~h} .{ }^{1} \mathrm{H}$ NMR (300 MHz, $\left.\mathrm{CDCl}_{3}\right): \delta 4.990-4.886\left(\mathrm{~d}, 1 \mathrm{H}, \mathrm{CH}^{\mathrm{i}}\right), 4.565-$ $4.473\left(\mathrm{t}, 8 \mathrm{H}, \mathrm{CH} H^{\mathrm{j}, \mathrm{k}}\right), 3.489-3.326\left(\mathrm{br}, \mathrm{m}, \mathrm{CH}^{\mathrm{d}, \mathrm{g}}\right), 2.708(\mathrm{~s}$, $\left.1 \mathrm{H}, \mathrm{CH}^{\mathrm{a}}\right), 2.389-2.275\left(\mathrm{br}, \mathrm{m}, \mathrm{CH}^{\mathrm{e}}\right), 2.169-1.992(\mathrm{~m}, \mathrm{br}$, $\left.\mathrm{CH}^{\mathrm{b}, \mathrm{f}}\right), 1.308-1.132\left(\mathrm{br}, \mathrm{m}, \mathrm{CH}^{\mathrm{c}, \mathrm{h}}\right)$ (Fig. 2). FT-IR (KBr,

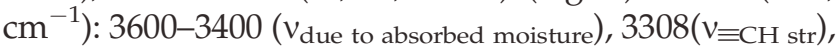
$2979\left(v_{\mathrm{CH}}\right.$ str $), 1696(\mathrm{~N}-\mathrm{CO}-$, str. for cyclic tertiary amide $), 1514$, $1426\left(v_{\mathrm{C}-\mathrm{N} \text { str. }),}, 1361\left(v_{\mathrm{C}-\mathrm{O}}\right.\right.$, bending, med $), 1256,1196,1097$ $\left(v_{\mathrm{C}-\mathrm{C}-\mathrm{C} \text { bending, medium }}\right), 1086\left(v_{\mathrm{C}=\mathrm{S} \text { str }}\right), 1083\left(v_{\mathrm{C}-\mathrm{S} \text { str }}\right)$, $1008\left(v_{\mathrm{C}}-\mathrm{C}\right.$ str., weak $), 832\left(v_{\mathrm{C}}-\mathrm{H}\right.$ bending of the ring, medium $)$, 649 ( $v_{C-S}$ str) (Fig. 3). UV (DMSO): 270 and $292 \mathrm{~nm}$ (Fig. 4, curve C).

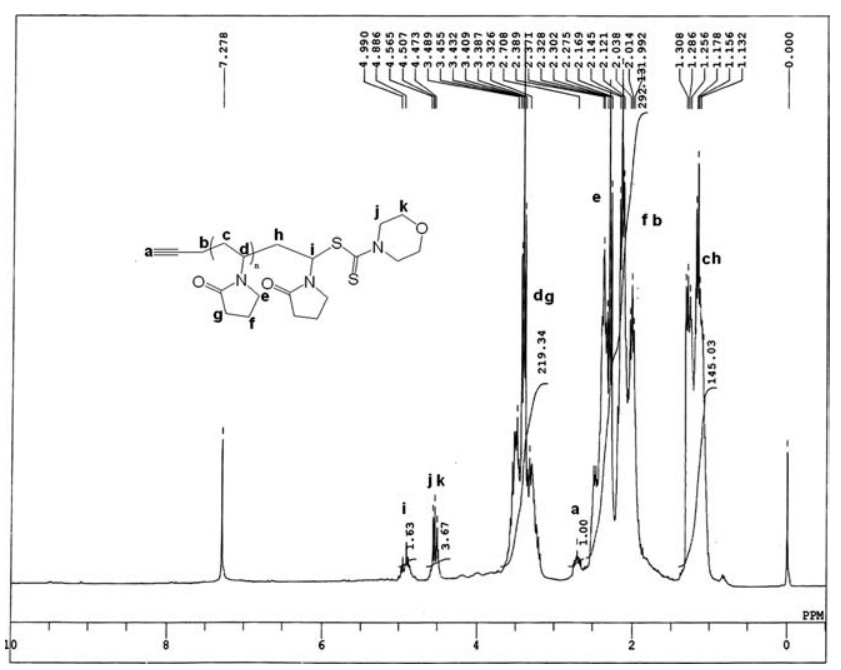

Figure $2{ }^{1} \mathrm{H}$ NMR spectra of PMDC_NVP polymer 


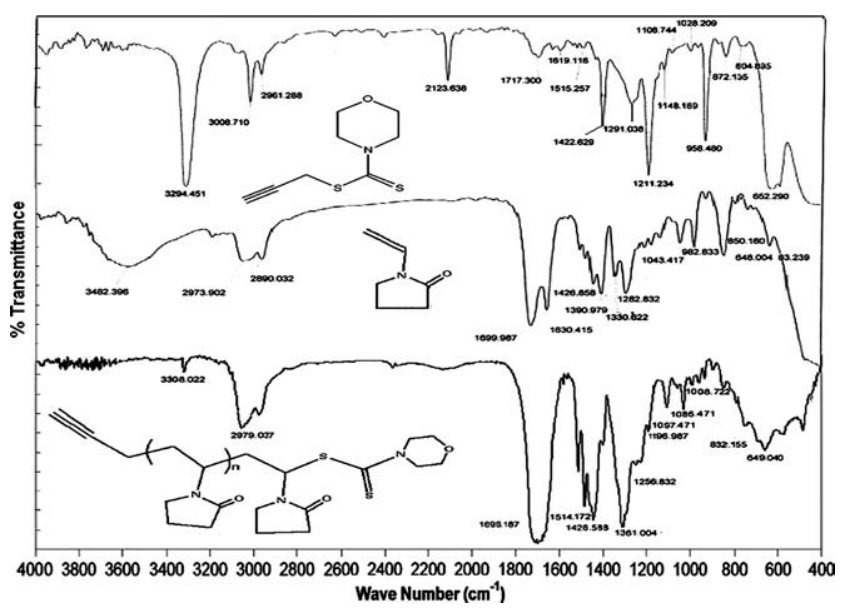

Figure 3 IR spectra of prop-2-ynyl morpholine-4-carbodithioate (PMDC) and its polymer PMDC_NVP.

\section{Polymer synthesis and characterization}

The protocol used for the RAFT synthesis of a linear poly ( $N$-vinyl pyrrolidone) homopolymer was as follows: PMDC RAFT agent $(201 \mathrm{mg}, 1 \mathrm{mmol})$ and NVP monomer $(11 \mathrm{~mL} ; 100 \mathrm{mmol})$ were added into a $100 \mathrm{~mL}$ Schlenk flask, degassed using three freezepump-thaw cycles and refilled with nitrogen for 30 min. Anhydrous toluene $(11 \mathrm{~mL}, 80 \mathrm{wt} \%)$ was added via a $\mathrm{N}_{2}$-purged glass syringe and the mixture was purged with nitrogen for $10 \mathrm{~min}$. 2,2'-Azobis(2-methylpropionitrile) (AIBN, $32.8 \mathrm{mg}, 0.2 \mathrm{mmol}$, PMDC/ AIBN molar ratio $=5: 1$ ) was added at last under a positive pressure of nitrogen before the flask was immersed in a preheated oil bath at $55^{\circ} \mathrm{C}$. This degassed stock solution was divided into eleven dry and degassed polymerization glass tubes. Aliquots (typically $0.20 \mathrm{~mL}$ ) were periodically extracted for GPC and ${ }^{1} \mathrm{HNMR}$ analyses for conversion. In the latter case, spectra were recorded in $\mathrm{CDCl}_{3}$ and the signals due to the residual vinyl protons of monomer at $\delta 4.31-4.42(2 \mathrm{H}) \mathrm{ppm}$ and $\delta 7.01(1 \mathrm{H})$ were compared with $3.489-3.326 \mathrm{ppm}[(\mathrm{d})$ and $(\mathrm{g})$ in Fig. 2] for the $-\mathrm{NCH}$, and $-\mathrm{NCOCH}_{2}$ of the corresponding polymer. After $9 \mathrm{~h}$, the polymerization was terminated by exposure to air and cooling the reaction flask in liquid nitrogen. Toluene was removed under reduced pressure and polymer was precipitated in hexane. For purification of polymer, precipitate was dissolved in minimum amount of DMF and reprecipitated into excess of hexane to remove any unreacted monomer. The conversion of monomer to polymer was obtained $72 \%$. Finally, the homopolymer was dried for $24 \mathrm{~h}$ in a vacuum oven at $50^{\circ} \mathrm{C}$ gave light pink powder. The molecular weight $\left(M_{n}\right)$ and molar mass dispersity $(Đ m)$ of the obtained polymer were determined as 9430 and 1.15, respectively. PMDC will be examined as chain-transfer agent in the RAFT polymerization of NVP. The signals at $\delta 4.565-4.473 \mathrm{ppm}$ correspond to the ring protons of PMDC units. The appearance of the signals at 4.565-4.473 ppm indicates that the dithioester formed from PMDC reacted with primary or propagating radicals (Scheme 3 and Fig. 2), and that the PMDC moiety remained at the end of polymer chain. The appearance of cyclic tertiary amide at $1696 \mathrm{~cm}^{-1}$ for $\mathrm{N}-\mathrm{C}=\mathrm{O}$; 1514, $1426 \mathrm{~cm}^{-1}$ for $\mathrm{C}-\mathrm{N}$ stretching ${ }^{32}$ and $1361 \mathrm{~cm}^{-1}$ for $\mathrm{C}-\mathrm{O}$ bending of $\mathrm{N}$-vinylpyrrolidone (Fig. 3). The band of PMDC RAFT agent appears at $1086 \mathrm{~cm}^{-1}$ for $\mathrm{C}=\mathrm{S}$ stretching and $649 \mathrm{~cm}^{-1}$ for $\mathrm{C}-\mathrm{S}$ stretching. These bands in FTIR spectra of polymer ${ }^{33-37}$ support the successful RAFT polymerization of $\mathrm{N}$-vinyl pyrrolidone (Fig. 3). UV analyses show the peak at $254 \mathrm{~nm}$, which is due to the morpholine unit and two peaks at 271 and $290 \mathrm{~nm}$ for carbodithioate unit (Fig. 4, curve A). Figure 4 (curve B) shows two maxima in which band at $280 \mathrm{~nm}$ are due to propargyl group and other one at $257 \mathrm{~nm}$ is due to MDC. PMDC-NVP polymer shows three maxima on 256, 280, and $309 \mathrm{~nm}$, i.e., due to the MDC, propargyl, and $N$-vinyl pyrrolidone units. The presence of these peaks in polymer supports the successful RAFT polymerization (Fig. 4, curve C).

\section{RESULTS AND DISCUSSION}

\section{Kinetic studies}

A linear relationship between $\ln [M]_{0} /[M]_{t}$ and reaction time is shown in Figure 5. The first-order kinetics indicates that the concentration of free radicals remained constant during the polymerization. ${ }^{38-40}$ The plots of $M_{n}$ and molar mass dispersity versus monomer conversion of NVP are shown in Figure 6. $M_{n}$ values increased linearly with conversion, while the molar mass dispersity remained in a relative low value

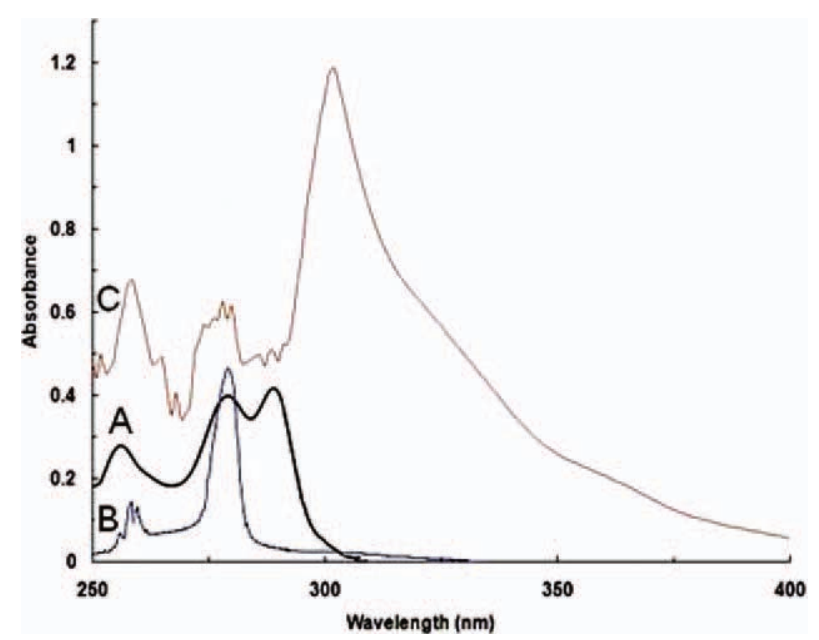

Figure 4 UV spectra of (a) morpholine-4-carbodithioate (MDC), (b) prop-2-ynyl morpholine-4-carbodithioate (PMDC) and (c) PMDC_NVP polymer. [Color figure can be viewed in the online issue, which is available at wileyonlinelibrary.com.] 


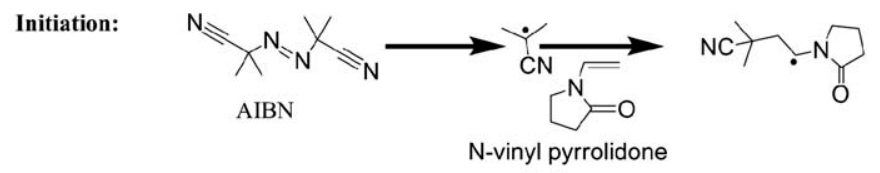

Reversible Addition-Fragmentation of a dithioester: Prop-2-ynyl morpholine-4-carbodithioate<smiles>C#CCSC(=S)N1CCOCC1</smiles>

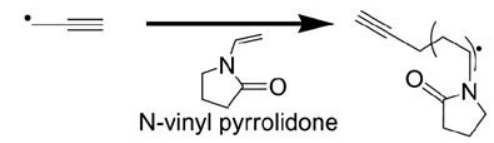

Addition-Fragmentation equilibrium between active and dormant chains:

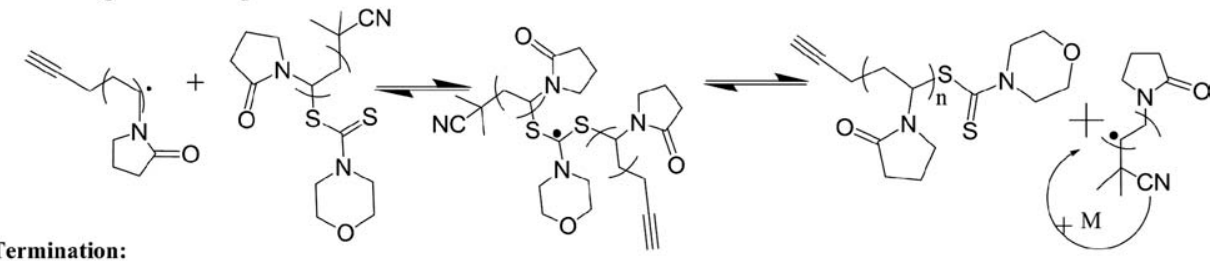

Termination:

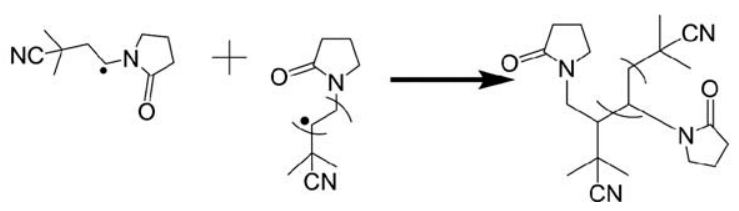

Scheme 3 RAFT mechanism in the presence of prop-2-ynyl morpholine-4-carbodithioate.

(1.50-1.15). These results suggest that PMDC is an effective RAFT agent for controlled the polymerization of NVP at the reported experimental conditions.

Living radical polymerization of NVP: Chain Extension of PNVP

To confirm further that the polymerization is a "living" process, a chain extension experiment was car-

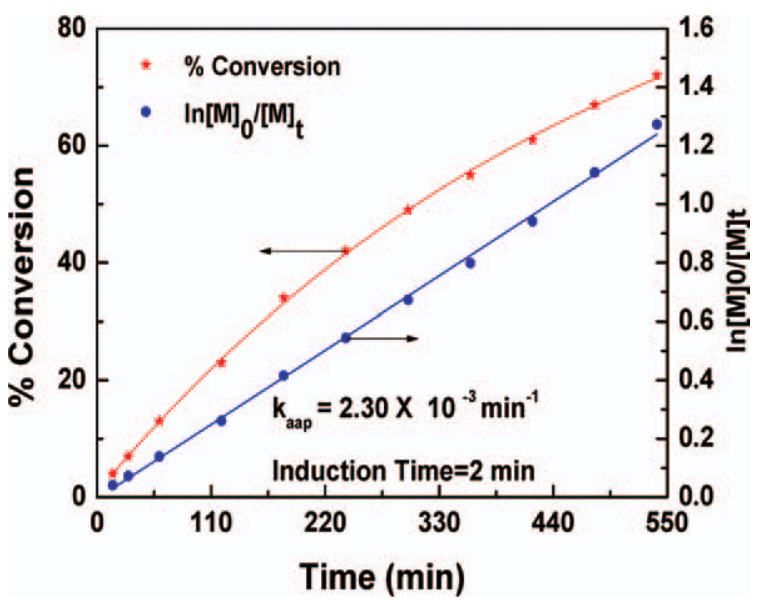

Figure 5 Kinetic plot to determine $K_{\text {aap }}$ constant. [Color figure can be viewed in the online issue, which is available at wileyonlinelibrary.com.] ried out using obtained polymer as the macro-CTA using the molar ratio [NVP]: [Macro-CTA]: [AIBN] $=100(1 \mathrm{mmol}=0.11 \mathrm{~mL}): 1(0.01 \mathrm{mmol} \approx 110 \mathrm{mg}$ of $M_{n}$ 9430) : $0.2(0.01 \mathrm{mmol}=1.64 \mathrm{mg})$ in $20 \mathrm{~mL}$ of toluene. This mixture was placed in a reaction ampule. After three freeze-evacuate-thaw cycles, the polymerization mixture was stirred at $55^{\circ} \mathrm{C}$ for $12 \mathrm{~h}$. The plot of the monomer $\ln \left([M]_{o} /\left[M_{t}\right]\right)$ and (\%)

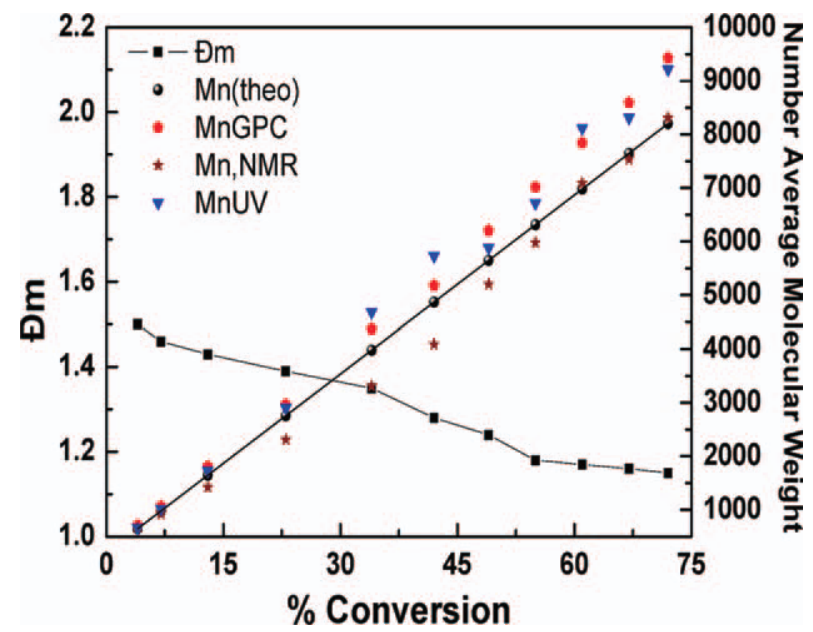

Figure 6 Main graph $M_{n}$ vs \% conversion. [Color figure can be viewed in the online issue, which is available at wileyonlinelibrary.com.] 


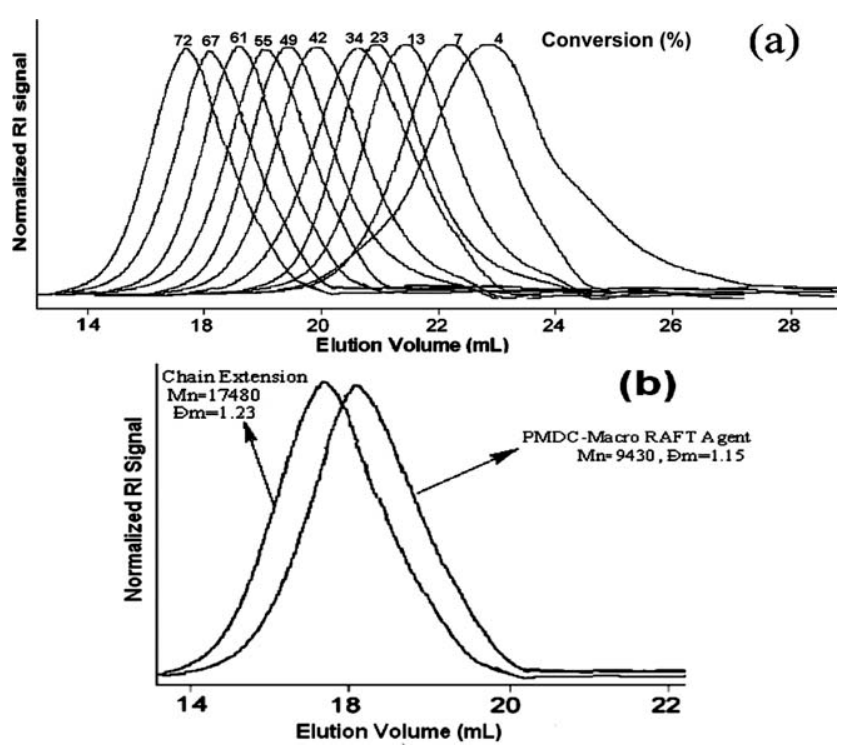

Figure 7 (a) Trace of GPC chromatograms of PMDC_NVP at different time (b) chain extension of NVP (52\% conversion).

conversion versus time (Fig. 5) indicates that the monomer (\%) conversion increases almost linearly upto around $52 \%$ conversion and followed the pseudo-first-order kinetics. ${ }^{41,42}$ This behavior may be due to auto-acceleration (gel-effect) at higher monomer conversions. Molecular weight $\left(M_{n}=9430\right)$ increases linearly with (\%) conversion upto $52 \%\left(M_{n}\right.$ $=17,480)$ [Figs. 6 and 7(b)]. The observed molecular weights drifted gradually from the corresponding theoretical values with increase in conversion. The corresponding Đm increases gradually from 1.15 to 1.23 [Figs. 6 and $7(\mathrm{~b})$ ] with increase in (\%) conversion, this broadening is due to the high viscosity of the medium. Figures $7(a, b)$ show the corresponding gradual peak shifting of the GPC chromatograms in the above-mentioned kinetic study. ${ }^{1} \mathrm{H}$ NMR spectrum shows the consistent growth of polymer chain as well as propargyl group of CTA is incorporated at $\alpha$-end of the polymer chain, while $\omega$-end remains with terminal morpholine dithiocarbamate. This successful chain extension and characterization of polymers suggests that the polymerization is a living process.

\section{Mechanism of RAFT polymerization}

RAFT is based on process that consists of the simple introduction of a small amount of PMDC (CTA) in a conventional free-radical system. The transfer of the PMDC between growing radical chains, present at a very low concentration, and dormant polymeric chains, present at a higher concentration, will regulate the growth of the molecular weight and limit the termination reactions. The mechanism of RAFT polymerization, as it is generally accepted, is depicted in Scheme 1.

Initiation

Initiation occurs via the decomposition of the free radical initiator (AIBN). The radical species issued from the decomposition of the radical initiator reacts with the monomer $\left(k_{i}\right)$ which starts an active polymerizing chain.

Reversible addition fragmentation

It shows that growing polymer chain rapidly adds to the reactive $\mathrm{C}=\mathrm{S}$ bond of the PMDC $\left(k_{\mathrm{add}}\right)$ to form a radical intermediate (the radical initiator may add directly onto the PMDC, before reacting with any monomer). The fragmentation of the intermediate occurring reversibly either toward the initial growing chain $\left(k_{\mathrm{add}}\right)$ or to free the re-initiating group (R) and a macro chain-transfer agent (macro-CTA) $\left(k_{\text {frag }}\right)$.

Re-initiation of fragmented radical

The propargyl radical group can then re-initiate polymerization $\left(k_{\text {re-in }}\right)$ by reacting with the $N$-vinyl pyrrolidone and start a new polymer chain, which will propagate $\left(k_{p}\right)$ or react back on the macro-CTA $\left(k_{\text {frag }}\right)$.

\section{Equilibration}

This is the fundamental step in the RAFT process which traps the majority of the active propagating species into the dormant thiocarbonyl compound.

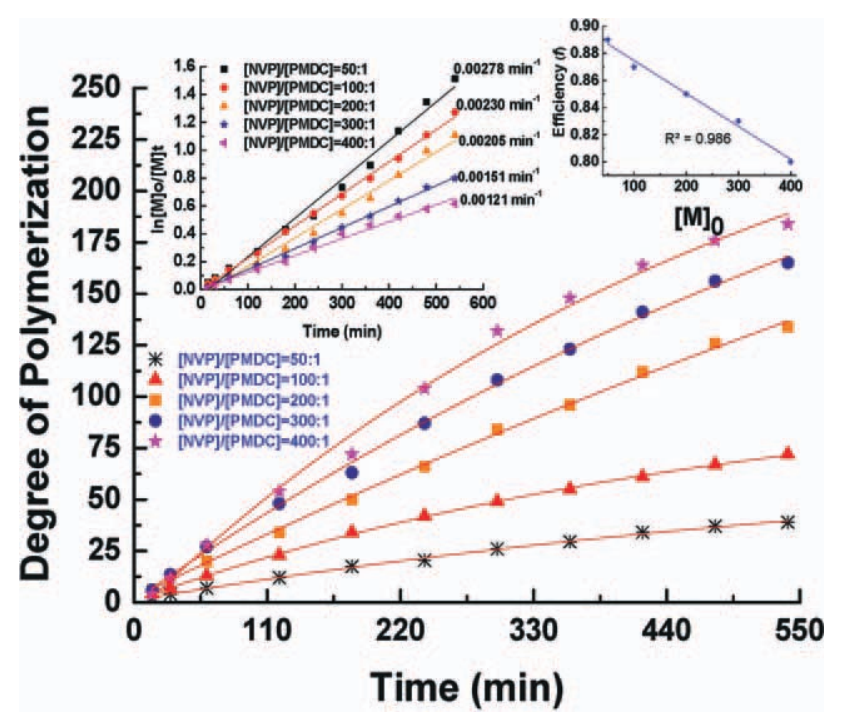

Figure 8 Effect of monomer concentration on RAFT agent efficiency. [Color figure can be viewed in the online issue, which is available at wileyonlinelibrary.com.] 
TABLE I

Experimental Conditions for PMDC_NVP Prepared by RAFT Using PMDC as CTA ${ }^{\mathrm{a}}$

\begin{tabular}{|c|c|c|c|c|c|c|c|c|}
\hline Run & Conv. & Time & $\ln \left[M_{0} / M_{t}\right]$ & $M_{n(\text { Theo })}$ & $M_{n(\mathrm{GPC})}$ & $M_{n(\mathrm{NMR})}$ & $M_{n(\mathrm{UV})}$ & Đm \\
\hline 1 & 4 & 15 & 0.04082 & 646 & 710 & 670 & 660 & 1.50 \\
\hline 2 & 7 & 30 & 0.07257 & 979 & 1060 & 920 & 1020 & 1.46 \\
\hline 3 & 13 & 60 & 0.13926 & 1646 & 1810 & 1430 & 1730 & 1.43 \\
\hline 4 & 23 & 120 & 0.26136 & 2757 & 2970 & 2310 & 2900 & 1.39 \\
\hline 5 & 34 & 180 & 0.41552 & 3980 & 4370 & 3310 & 4680 & 1.35 \\
\hline 6 & 42 & 240 & 0.54473 & 4869 & 5180 & 4090 & 5730 & 1.28 \\
\hline 7 & 49 & 300 & 0.67334 & 5647 & 6210 & 5200 & 5880 & 1.24 \\
\hline 8 & 55 & 360 & 0.79851 & 6314 & 7020 & 5980 & 6720 & 1.18 \\
\hline 9 & 61 & 420 & 0.94161 & 6981 & 7840 & 7090 & 8120 & 1.17 \\
\hline 10 & 67 & 480 & 1.10866 & 7647 & 8600 & 7540 & 8310 & 1.16 \\
\hline 11 & 72 & 540 & 1.27297 & 8203 & 9430 & 8310 & 9220 & 1.15 \\
\hline
\end{tabular}

${ }^{a}[\mathrm{NVP}]=1 \mathrm{Mol} . \mathrm{L}^{-1},[\mathrm{PMDC}]=1 \times 10^{-2} \mathrm{Mol} . \mathrm{L}^{-1},[\mathrm{AIBN}]=2 \times 10^{-3} \mathrm{Mol} . \mathrm{L}^{-1}$, temperature $=55^{\circ} \mathrm{C}$, time $=9 \mathrm{~h}$, solvent $=$ toluene, initiator efficiency, $f=0.91$, apparent rate constant $\left(K_{\text {app }}\right)=2.3 \times 10^{-3} \mathrm{~min}^{-1}$ and induction time $=2$ min (obtained from the slope of $\ln [\mathrm{Mo} / \mathrm{Mt}]$ versus time $(t)$.

This limits the possibility of chain termination. Once the initial CTA has been entirely consumed, the macro-CTA agent is solely present in the reaction medium and enters equilibrium. This equilibrium is considered the main equilibrium, and a rapid exchange between active and dormant (thiocarbonylthio capped) chains ensures equal probability for all chains to grow, therefore leading to the production of polymers of narrow molecular weight distribution. Such radical intermediates may also be involved in a variety of side reactions during polymerization, including termination with a propagating polymeric chain.

\section{Termination}

It describes the unavoidable reactions of termination present in all free-radical polymerization systems, by either combination $\left(k_{\mathrm{tc}}\right)$ or disproportionation $\left(k_{\mathrm{td}}\right)$.
However, as the termination reactions are kept to a minimum, the final product consists of a large majority of polymeric chains showing the re-initiating group (R) at one end and the thiocarbonyl-thio group at the other.

\section{Optimization of reaction parameters}

Influence of different mole ratio of different NVP and PMDC

According to the mechanism ${ }^{4}$ (Scheme 3), in order to control the polymerization process, increasing the concentration of $N$-vinyl pyrrolidone after a certain point, was slow down the transformation of PMDC into dormant polymer chains. Therefore, a study of the polymerization of NVP at various molar ratios of $[\mathrm{NVP}]_{0} /[\mathrm{PMDC}]_{0}$ was carried out at $55^{\circ} \mathrm{C}$. Figure 8 shows the effect of initial monomer concentration with respect to CTA $\left([M]_{\mathrm{o}}:[\mathrm{CTA}]_{\mathrm{o}}=50: 1,100: 1\right.$,

TABLE II

Molar Mass and Conversion Data for Poly(N-Vinyl Pyrrolidone) Samples Prepared Via Different NVP and PMDC Mole Ratio at $55^{\circ} \mathrm{C}$

\begin{tabular}{|c|c|c|c|c|c|c|c|c|c|}
\hline Run & $\begin{array}{l}\mathrm{NVP} \\
(\mathrm{mmol})\end{array}$ & $\begin{array}{l}\text { Solvent } \\
(\mathrm{mL})\end{array}$ & $\begin{array}{c}\text { AIBN } \\
(\mathrm{mmol})\end{array}$ & $\begin{array}{l}\text { PMDC } \\
(\mathrm{mmol})\end{array}$ & $M_{n \text { Theo }}$ & $M_{n \mathrm{GPC}}$ & Đm & Conv (\%) & $\begin{array}{c}\text { PMDC/AIBN } \\
\text { (mole ratio) }\end{array}$ \\
\hline 1 & 100 & 10 & 0.2 & 0.4 & 6536 & 6950 & 1.25 & 57 & $2: 1$ \\
\hline 2 & 100 & 10 & 0.2 & 0.6 & 6981 & 7590 & 1.18 & 61 & $3: 1$ \\
\hline 3 & 100 & 10 & 0.2 & 0.8 & 7536 & 8470 & 1.16 & 66 & 4.1 \\
\hline 4 & $100^{\mathrm{a}}$ & 10 & 0.2 & 1.0 & 8203 & 9430 & 1.15 & 72 & $5: 1$ \\
\hline 5 & 100 & 10 & 0.2 & 2.0 & 10426 & 13030 & 1.14 & 74 & $10: 1$ \\
\hline Run & $\begin{array}{c}\text { NVP } \\
(\mathrm{mmol})\end{array}$ & $\begin{array}{l}\text { Solvent } \\
(\mathrm{ml})\end{array}$ & $\begin{array}{c}\text { AIBN } \\
(\mathrm{mmol})\end{array}$ & $\begin{array}{l}\text { PMDC } \\
(\mathrm{mmol})\end{array}$ & $M_{n \text { Theo }}$ & $M_{n \mathrm{GPC}}$ & Đm & Conv (\%) & $\begin{array}{c}\mathrm{NVP} / \mathrm{PMDC} \\
\text { (mole ratio) }\end{array}$ \\
\hline 6 & 50 & 10 & 0.2 & 1 & 4535 & 5100 & 1.13 & 78 & $50: 1$ \\
\hline 7 & $100^{a}$ & 10 & 0.2 & 1 & 8203 & 9430 & 1.15 & 72 & $100: 1$ \\
\hline 8 & 200 & 10 & 0.2 & 1 & 15094 & 17760 & 1.20 & 67 & 200.1 \\
\hline 9 & 300 & 10 & 0.2 & 1 & 18557 & 22360 & 1.23 & 55 & $300: 1$ \\
\hline 10 & 400 & 10 & 0.2 & 1 & 20651 & 25810 & 1.29 & 46 & $400: 1$ \\
\hline
\end{tabular}

${ }^{\mathrm{a}}[\mathrm{NVP}]=1 \mathrm{Mol} . \mathrm{L}^{-1},[\mathrm{PMDC}]=1 \times 10^{-2} \mathrm{Mol} . \mathrm{L}^{-1},[\mathrm{AIBN}]=2 \times 10^{-3} \mathrm{Mol} . \mathrm{L}^{-1}$, temperature $=55^{\circ} \mathrm{C}$, time $=9 \mathrm{~h}$, solvent $=$ toluene. 


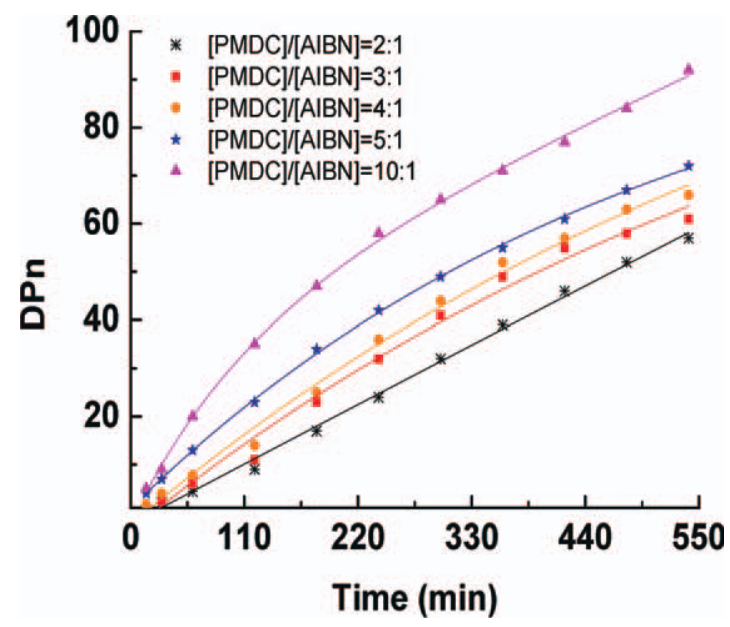

Figure 9 Effect of RAFT agent concentration. [Color figure can be viewed in the online issue, which is available at wileyonlinelibrary.com.]

$200: 1,300: 1$, and $400: 1$ ). This plot gave the firstorder kinetics for each initial monomer concentration with apparent reaction rate constants, $K_{\text {app }}$, i.e., 2.78 , $2.3,2.05,1.51$, and $1.21 \times 10^{-3} \mathrm{~min}^{-1}$, respectively (Tables I and II). As we increase the [NVP]/[PMDC] ratio, the apparent rate constant decreases from 2.78 $\times 10^{-3} \mathrm{~min}^{-1}$ to $1.21 \times 10^{-3} \mathrm{~min}^{-1}$ and efficiency of CTA decreases from 0.89 to 0.80 , respectively, while the degree of polymerization increases continuously. The decrease in percentage of conversion from $78 \%$ to $46 \%$ is due to the viscosity of the reaction medium, which hinders the movement of the propagating chains towards monomer due to decrement in conversion. However, at 100 equivalents of the $[\mathrm{NVP}] /[\mathrm{PMDC}]$ ratio, the propagating growth of chain becomes linear (Fig. 5), which supports the controlled polymerization of NVP by PMDC chain transfer agent. Although there was no apparent variation in molar mass dispersity (Đm) with initial monomer percentage conversion, the molar mass dispersity (Đm) increased over the course of the reaction from 1.13 to 1.29 as the mole ratio of $[\mathrm{NVP}]_{0} /[\mathrm{AIBN}]_{0}$ increased (Table I, Fig. 8).
Influence of different PMDC and AIBN ratio

Based on the RAFT polymerization mechanism (Scheme 3), the ratio of PMDC and AIBN should have a significant influence on the molar mass dispersity of polymer. Increasing the concentration of initiator or decreasing the concentration of RAFT agent slowed down the transformation of PMDC into dormant polymer chains. At the same time, the probability of termination between two radicals increases. As a result, the obtained polymer has got a broader molar mass dispersity, i.e., 1.14 to 1.25. The influence of different PMDC/AIBN ratio on the molecular weight has been listed in Table II and Figure 9 shows retardation phenomenon in the polymerization process of system. This retardation is due to (i) specificity for the expelled radical to add to the RAFT agent rather than to monomer as the ratio of $[\mathrm{PMDC}]_{0} /[\mathrm{AIBN}]_{0}$ increased $^{43,44}$ (ii) the cross termination, i.e., the termination between the propagation free radical and intermediate. ${ }^{45,46}$

\section{Effect of temperature}

To find out the favorable and optimized temperature for RAFT process, number of experiments was carried out (Table III and Fig. 10) at five different temperatures $45,50,55,60$, and $65^{\circ} \mathrm{C}$, respectively. As shown in Table III, the conversion and apparent rate constants increases with increase in temperature, among them $55^{\circ} \mathrm{C}$ was found best reaction temperature for RAFT polymerization of NVP. As shown in runs $1-5$ of Table III, \% conversion increases from 55 to 80 with increase in temperature from $45^{\circ} \mathrm{C}$ to $65^{\circ} \mathrm{C}$. Thus, when the reaction was performed at $45^{\circ} \mathrm{C}$ (run 1 of Table III), 55\% conversion was observed in $9 \mathrm{~h}$ with 1.44 molar mass dispersity. In same time at $50^{\circ} \mathrm{C}$ (run 2 of Table III), $64 \%$ conversion with 1.28 molar mass dispersity, at $55^{\circ} \mathrm{C}$ (run 3 of Table III), $72 \%$ conversion with 1.15 molar mass dispersity, at $60^{\circ} \mathrm{C}$ (run 4 of Table III), $75 \%$ conversion with 1.23 molar mass dispersity and at $65^{\circ} \mathrm{C}$ (run 5 of Table III), 80\% conversion with 1.34 molar

TABLE III

Effect of Temperature Variation to Polymerize N-Vinyl Pyrrolidone with PMDC RAFT Agent

\begin{tabular}{|c|c|c|c|c|c|c|c|c|c|}
\hline \multirow[b]{3}{*}{$\mathrm{T}\left({ }^{\circ} \mathrm{C}\right)$} & \multirow[b]{3}{*}{$\% \mathrm{C}$} & \multirow[b]{3}{*}{$K_{\text {aap }} \times 10^{-3}$} & \multirow[b]{3}{*}{$1 / T \times 1000$} & \multirow[b]{3}{*}{$\ln (\mathrm{K} / \mathrm{T})$} & \multicolumn{5}{|c|}{ Thermodynamic properties } \\
\hline & & & & & \multicolumn{2}{|c|}{$\begin{array}{c}\text { Using Arrhenius } \\
\text { equation }\end{array}$} & \multicolumn{3}{|c|}{ Using Eyring equation } \\
\hline & & & & & $\begin{array}{c}E_{a} \\
(\mathrm{KJ} / \mathrm{mol})\end{array}$ & $\ln \mathrm{A}$ & $\begin{array}{c}\Delta H^{\ddagger} \\
\left(\mathrm{kJ} \mathrm{mol}{ }^{-1}\right)\end{array}$ & $\begin{array}{c}\Delta S^{\ddagger} \\
\left(\mathrm{J} \mathrm{mol}^{-1} \mathrm{~K}^{-1}\right)\end{array}$ & $\begin{array}{c}\Delta G^{\ddagger} \\
\left(\mathrm{kJ} \mathrm{mol}{ }^{-1}\right)\end{array}$ \\
\hline $45(318 K)$ & 55 & 1.53 & 3.145 & -12.2445 & & & & & \\
\hline 50 (323K) & 64 & 1.90 & 3.096 & -12.0436 & & & & & \\
\hline $55(328 \mathrm{~K})$ & 72 & 2.30 & 3.049 & -11.8679 & 31.02 & 5.27 & 28.29 & -210.16 & 97.23 \\
\hline $60(333 \mathrm{~K})$ & 75 & 2.67 & 3.003 & -11.7338 & & & & & \\
\hline $65(338 K)$ & 80 & 3.07 & 2.959 & -11.6091 & & & & & \\
\hline
\end{tabular}




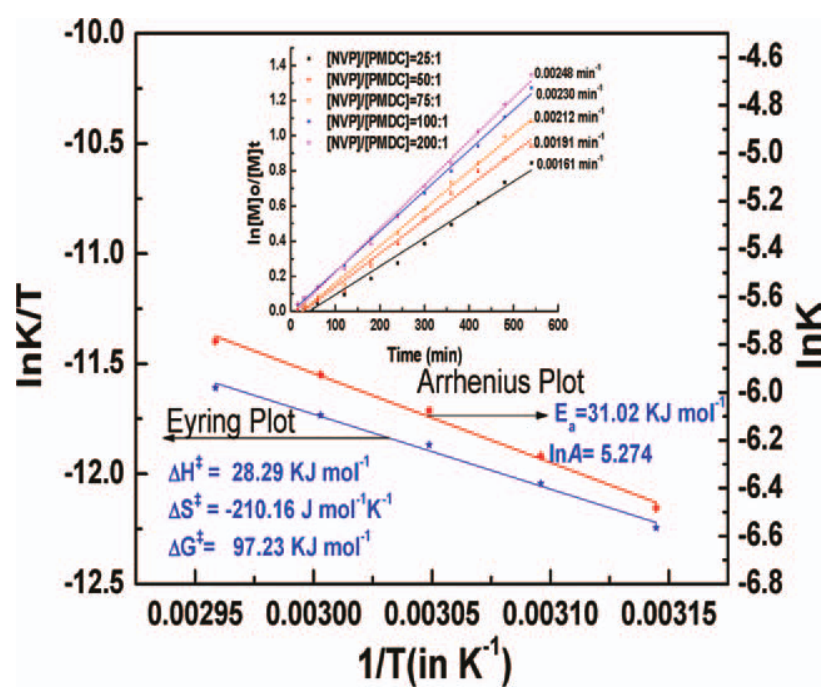

Figure 10 Effect of temperature concentration with regard to Eyring and Arrhenius equation. [Color figure can be viewed in the online issue, which is available at wileyonlinelibrary.com.]

mass dispersity were found. Therefore, RAFT polymerization at $55^{\circ} \mathrm{C}$ is more favorable due to good conversion with narrow molar mass dispersity. The temperature dependency of the apparent rate constants $\left(k_{\text {aap }}\right)$, the magnitudes of the activation enthalpy $\left(\Delta \mathrm{H}^{\ddagger}\right)$ and activation entropy $\left(\Delta \mathrm{S}^{\ddagger}\right)$ as well as activation energy $\left(E_{a}\right)$ were determined by evaluation of the resulting straight Eyring correlations through the Eyring and Arrhenius plot for the logarithmic values of the rate constant versus $1 / T$ (Fig. 10). The $\Delta S^{\ddagger} \approx-210.16 \mathrm{~J} \mathrm{~mol}^{-1} \mathrm{~K}^{-1}$, the reaction of polymerization shows negative activation entropy which allows a greater flexibility of the activated complex. Due to less rigid structures at the transition state, ${ }^{-} \Delta S^{\ddagger}$ suggests that at transition state, movement of reactants is highly restricted, which supports the progress of the reaction with time. The activation energy $E_{a}\left(31.02 \mathrm{~kJ} \mathrm{~mol}^{-1}\right)$ and $\Delta H^{\ddagger}$ $\left(28.29 \mathrm{~kJ} \mathrm{~mol}^{-1}\right)$ were very close to each other suggesting the feasibility of the reaction.

\section{CONCLUSION}

This is the first report of the controlled radical polymerization of NVP with newly synthesized prop-2ynyl morpholine-4-carbodithioate (PMDC) as chain transfer agent. PMDC reagent was found effective chain transfer agent to polymerize $N$-vinyl pyrrolidone through RAFT process. The optimized concentration ratio of reactants was found [NVP] : [PMDC] $:[\mathrm{AIBN}]=100: 1: 0.2$. Control on the rate of the polymerization was confirmed by the formation of polymer of predetermined molecular weight. The synthesized poly(NVP) shows narrow molar mass dispersity (Đm) between 1.50 and 1.15 .
The authors thank the Department of Chemistry, BHU, Varanasi (India) for providing spectral and analytical facilities.

\section{References}

1. Chiefari, J.; Chong, Y. K.; Ercole, F.; Krstina, J.; Le, T. P. T.; Mayadunne, R. T. A.; Meijs, G. F.; Moad, G.; Moad, C. L.; Rizzardo, E.; Thang, S. H. Macromolecules 1998, 31, 5559.

2. Le, T. P.; Moad, G.; Rizzardo, E.; Thang, S. H. PCT Int Appl 1998, WO98/01478.

3. Chiefari, J.; Rizzardo, E. In Handbook of Radical Polymerization; Matyjaszewski, K., Davis, T. P., Eds.; John Wiley: Hoboken, NJ, 2002; Chapter 12.

4. Boyer, C.; Bulmus, V.; Davis, T. P.; Ladmiral, V.; Liu, J.; Perrier, S. Chem Rev 2009, 109, 5402.

5. Srivastava, A.; Mishra, V.; Singh, S. K.; Kumar, R. J Appl Polym Sci 2010, 115, 2375.

6. Srivastava, A.; Mishra, V.; Singh, S. K.; Kumar, R. e-Polymers $2009,6,1$.

7. Chiefari, J.; Mayadunne, R. T. A.; Moad, G.; Rizzardo, E.; Thang, S. H. PCT Int Appl, 1999, W099/31144.

8. Coessens, V.; Pintaver, T.; Matyzaszewski, K. Prog Polym Sci 2001, 26, 337.

9. Stepto, R. F. T. Pure Appl Chem 2009, 81, 351.

10. Wan, D.; Satoh, K.; Kamigaito, M.; Okamoto, Y. Macromolecules 2005, 38, 10397.

11. Devasia, R.; Bindu, R. L.; Mougia, N.; Gnanou, Y. Macromol Symp 2005, 229, 8.

12. Bilalis, P.; Pitsikalis, M.; Hadjichristidis, N. J Polym Sci A 2006, 44, 659.

13. Yamago, S.; Ray, B.; Iida, K.; Yoshida, J. I.; Tada, T.; Yoshizawa, K.; Kwak, Y.; Goto, A.; Fukuda, T. J Am Chem Soc 2004, 126, 13908.

14. Ray, B.; Kotani, M.; Yamago, S. Macromolecules 2006, 39, 5259.

15. Yusa, S. I.; Yamago, S.; Sugahara, M.; Morikawa, S.; Yamamoto, T.; Morishima, Y. Macromolecules 2007, 40, 5907.

16. Yamago, S.; Kayahara, E.; Kotani, M.; Ray, B.; Kwak, Y.; Goto, A; Fukuda, T. Angew Chem Int Ed 2007, 46, 1304.

17. Mishra, V.; Kumar, R. Carbohydr Polym 2011, 86, 296.

18. Lu, X.; Gong, S.; Meng, L.; Li, C.; Yang, S.; Zhang, L. Polymer 2007, 48, 2835.

19. Pound, G.; Eksteen, Z.; Pfukwa, R.; McKenzie, J. M.; Lange, R. F. M.; Klumperman, B. J Polym Sci A 2008, 46, 6575.

20. Pound, G.; Aguesse, F.; McLeary, J. B.; Lange, R. F. M.; Klumperman, B. Macromolecules 2007, 40, 8861.

21. Oishi, T.; Ogata, M. Jpn Kokai Tokkyo Koho JP 2003, 175,320 (Cl. B01D69/08) JP Appl 2001/309,673, 5 Oct. 2001; 11 pp (Japan).

22. Oishi, T.; Ogata, M. Jpn. Kokai Tokkyo Koho JP 2003, 175,321 (Cl. B01D69/08) 24 June 2003, 12 pp (Japan).

23. Castano, F.; Jorge, L.; Uribarri, H.; Evange, L.; Aleman, S.; Alejandro, R. M. C. Farmaceuticas 2002, 33, 16-19 (Span), Association Pharmaceutica Mexicana.

24. Schuer, J. P. PCT Int Appl, WO02, 55,114 (Cl. A61L9/01), 18 July 2002,Schuer, J. P. DE Appl 10, 100,595, 9 Jan 2001, 47 pp (Ger.).

25. Gaenger, K.; Florig, E. Eur Pat Appl EP, 1,192,931 (Cl. A61K7/ 06), 3 Apr 2002, Appl 2001/128,662, 1 Dec. 2001; 11pp (Ger.).

26. Kroeppe, R.; Bleckmann, A. Eur Pat Appl EP, 1,192,929 (Cl. A61K7/00), 3 Apr 2002,Kroeppe, R.; Bleckmann, A. DE Appl 10,048,429, 29 Sep 2000; 14 pp (Ger.).

27. Oda, N.; Kasai, I.; Umeda, K. Jpn Kokai Tokkyo Koho, JP 2003, 183,904 (Cl. A41B17/00), 3 Jul 2003, Appl 2001/382,627, 17 Dec. 2001; 8 pp (Japan).

28. Perrier, S.; Takolpuckdee, P. J Polym Sci Polym Chem 2005, $43,5347$. 
29. Favier, A.; Charreyre, M.-T. Macromol Rapid Commun 2006, 27,653

30. Lowe, A. B.; McCormick, C. L. Prog Polym Sci 2007, 32, 283.

31. Qiu, X. P., Tanaka, F., Winnik, F. M. Macromolecules 2007, 40, 7069.

32. Thorn, G. D.; Ludwig, R. A. The Dithiocarbamates and Related Compounds; Elsevier: New York, 1962.

33. Mishra, V.; Kumar, R. Carbohydr Polym 2011, 83, 1534.

34. Marambio, O. G.; Pizarro, G. C.; Orell, M. J.; Geckeler, K. E. J Appl Polym Sci 2009, 113, 1792.

35. Srivastava A.; Behari, K. J Appl Polym Sci 2006, 100, 2480.

36. Srivastava, A.; Mishra, D. K.; Tripathy, J.; Behari, K. J Appl Polym Sci 2009, 111, 2872.

37. Mishra, D. K.; Tripathy, J.; Mishra, M. M.; Behari, K. J Appl Polym Sci 2008, 110, 3455.

38. Chong, Y. K.; Le, T. P. T.; Moad, G.; Rizzardo, E.; Thang, S. H. Macromolecules 1999, 32, 2071.
39. Chiefari, J.; Chong, Y. K.; Ercole, F.; Krstina, J.; Jeffery, J.; Le, T. P. T.; Mayadunne, R. T. A.; Meijs, G. F.; Moad, C. L.; Rizzardo, E.; Thang, S. H. Macromolecules 1998, 31. 5559.

40. Mayadunne, R. T. A.; Rizzardo, E.; Chiefari, J.; Krstina, J.; Moad, G.; Postma, A.; Thang, S. H. Macromolecules 2000, 33, 243.

41. Maki, Y.; Mori, H.; Endo, T. Macromol Chem Phys 2007, 208, 2589.

42. Wadley, M. L.; Cavicchi, K. A. J Appl Polym Sci 2010, 115, 635.

43. Moad, G.; Chiefari, J.; Chong, Y. K.; Krstina, J.; Mayadunne, R. T. A.; Postma, A.; Rizzardo, E.; Thang, S. H. Polym Int 2000, 49, 993.

44. Barner-kowollik, C.; Quinn, J. F.; Morsley, D. R.; Davis, T. P. J Polym Sci Polym Chem 2001, 39, 1353.

45. Monteiro, M. J.; de Brouwer, H. Macromolecules 2001, 34, 349.

46. Kwak, Y.; Goto, A.; Tsujii, Y.; Murata, Y.; Komatsu, K.; Fukuda, T. Macromolecules 2002, 35, 3026 